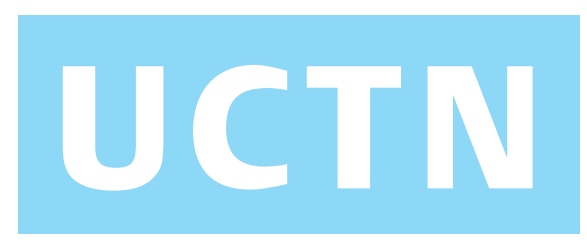

\title{
Capsule Endoscopy: In Difficult Cases the Capsule Can Be Ingested Through an Overtube
}

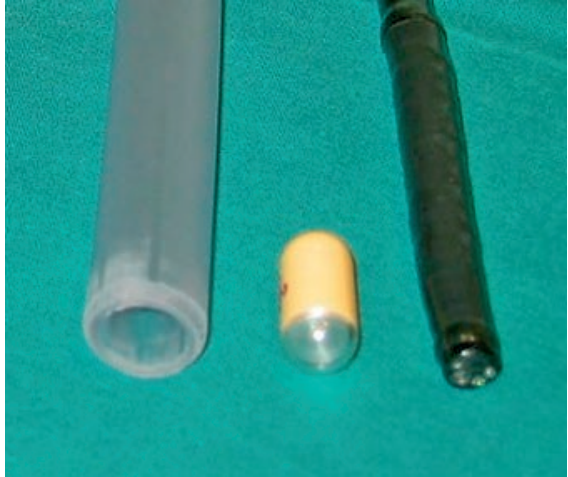

Figure 1 Overtube, capsule and scope.

Capsule endoscopy has become an important tool in the diagnosis of small-bowel diseases [1,2]. The M2A capsule is $11 \times 27 \mathrm{~mm}$ in size, and for most patients, swallowing the capsule does not pose any problems. However, some patients may have difficulties, and different methods of overcoming these have been described $[3,4]$. We describe the ingestion of an M2A capsule through an overtube.

A 46-year-old woman with a history of chronic iron-deficiency anemia was found to be in need of capsule endoscopy. She had to be sedated ( $2 \mathrm{mg}$ midazolam) to undergo an ordinary upper endoscopy and was not able to swallow the M2A capsule.

We constructed an overtube using a type of vacuum curettage tube, the Medena M0760 (AstraTech AB, Mölndal, Sweden) which is in daily use for vaginal surgery at our hospital. The external diameter is $17 \mathrm{~mm}$ and the internal diameter $13 \mathrm{~mm}$. The plastic cylinder was cut to a length of $45 \mathrm{~cm}$ and the distal end was tapered to ease intubation of the patient. An Olympus GIF 160 videoscope with an outer diameter of $8.6 \mathrm{~mm}$ was used (Figure $\mathbf{1}$ ).

The patient was sedated with $4 \mathrm{mg}$ of intravenous midazolam. The endoscope was inserted through the overtube (Figure 2 ), and both endoscope and overtube were intubated past the esophagogastric junction. The endoscope was retracted,

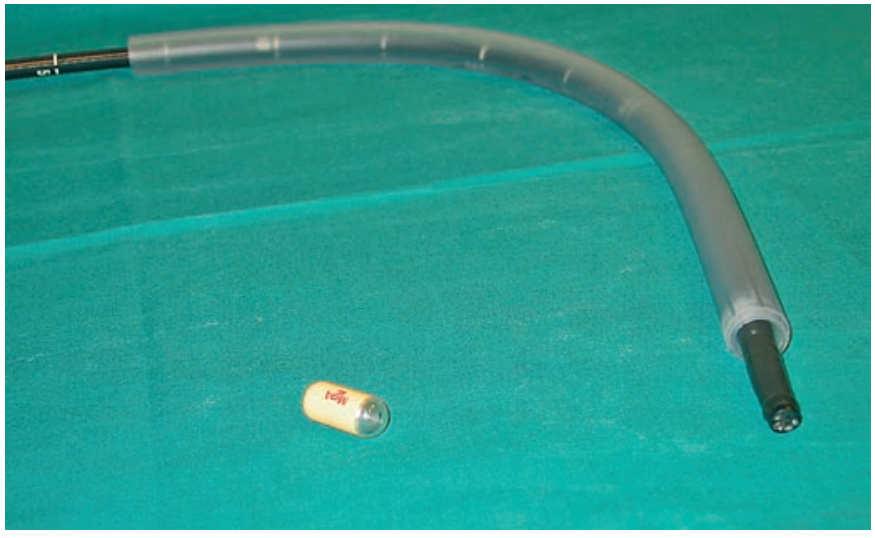

Figure 2 Scope inserted through an overtube.

and the M2A capsule was inserted into the overtube and then pushed into the fundus by reinsertion of the endoscope. Finally the overtube was removed.

The capsule endoscopy showed a polypoid tumour in the distal jejunum. The method of grasping the capsule in a polypectomy snare has been described previously.

We propose the use of an overtube in adults unable to swallow the M2A capsule, to avoid the danger of tracheal aspiration.

\section{E. Skogestad, J. K. Tholfsen}

Department of Internal Medicine, Innlandet Hospital Trust Lillehammer, Norway.

\section{References}

${ }^{1}$ Waye JD. Small-bowel endoscopy. Endoscopy 2003; 35: $15-21$

${ }^{2}$ Lewis B, Goldfarb N. Review article: the advent of capsule endoscopy - a not-sofuturistic approach to obscure gastrointestinal bleeding. Aliment Pharmacol Ther 2003; 17: 1085-1096

${ }^{3}$ Aabakken L, Scholz T, Ostensen AB et al. Capsule endoscopy is feasible in small children. Endoscopy 2003; 35: 798

${ }^{4}$ Aabakken L, Blomhoff JP, Jermstad T, Lynge AB. Capsule endoscopy in a patient with Zenker's diverticulum. Endoscopy 2003; 35: 799
Corresponding Author

\section{E. Skogestad, M.D.}

Department of Internal Medicine, Innlandet Hospital Trust Lillehammer 2629 Lillehammer

Norway

Fax: $\quad$ +47-612-72039

E-mail: erik.skogestad@sykehusetinnlandet.no 